\title{
Effective Use Of Group Projects In Online Learning
}

\author{
Robert Ekblaw, MS, Hudson Valley Community College, USA
}

\begin{abstract}
Group projects have long been used in face-to-face instruction to improve cognitive learning among its students. Group projects not only provide practical experience and allow students to practice the concepts they have learned, but also teach the students creative construction and group dynamics. As important as group projects have proven in conventional learning, they are rarely used in online education courses. This paper examines the foundations of effectively using group projects, and then demonstrates how to integrate them into online learning courses.
\end{abstract}

Keywords: Collaborative Learning; Group Projects; Distance Learning

\section{INTRODUCTION}

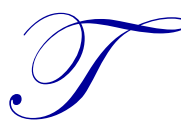

eamwork and group projects have found to be an effective tool for teaching higher-level cognitive functions. Students learn to incorporate disparage ideas and meld them into a single solution, while simultaneously learning to work and communicate within a group in a constructivist environment (Tarricone \& Luca, 2002). It has become a popular teaching method for higher education and advanced topics in secondary education. However, as higher education has increased its use of online courses, whether to increase enrollment, reduce faculty costs, or both, the propensity of group projects has reduced.

Why is that? It seems that many instructors believe that it is difficult to properly implement group projects and teamwork when the participants are scattered geographically and unable to meet face-to-face (Whatley, Beer, \& Staniford, 2001). An important factor to the success of project teams is effective communication (Hoegl \& Gemuenden, 2001), and many instructors feel that communication is much more difficult when the students cannot meet in person. Since instructor oversight is also a crucial factor in the success of group projects (Hoegl \& Gemuenden, 2001), their own difficulty communicating with remote students might also factor into the hesitation.

But does geographical separation really prevent effective communication? With the myriad of online and electronic communication methods, couldn't effective communication still drive group project teams? It might look different than the face-to-face communication and construction methods that dominated group projects in secondary education, but it could still be done.

We will examine that question, and determine the best methods of supporting effective teamwork in online group projects. We start with examining advances, experiments, and advice in literature. From there, we examine the methods and techniques of effective teamwork and communication, as well as tools to support online collaboration. We then propose a structure, or template, for designing an effective team-based project. Lastly, we conclude by examining what we have accomplished so far and what future research might unearth.

\section{LITERATURE REVIEW}

There have been several papers written about effective team projects in learning, although most of them focus on face-to-face learning. We'll examine these articles in an organized fashion, starting with the formulation of teams.

The formulation of teams is a crucial stage in project-based learning (Collaborative Learning: Group Work, 2014). The stronger the group, the better the result. Nearly all of the papers and researchers state the importance of having 
the instructor create the groups, instead of having the students choose their group mates. Careful selection of the group members helps ensure proper distribution and balance of skills and work ethic (Collaborative Learning: Group Work, 2014). Obviously, for the instructor to make an appropriate selection, he or she must have knowledge of the background, knowledge, and experience of the students. There are a variety of methods used to determine that information: a pre-test, a survey administered at the start of the course, case and course histories, and personal biographies. The importance of distributing the skills and methods of the group members allows for more interaction and broader investigation (Collaborative Learning: Group Work, 2014).

Once the teams are created, there is still preliminary work to be done before the actual project begins. The teams should be trained in team building and cohesion skills. Practice exercises are one of the best ways to educate them in group skills (Collaborative Learning: Group Work, 2014). The teams should also be trained in design methods, especially for technological or scientific projects like those in Computer Science, Electrical Engineering, Biomedicine, or similar studies (Paulus, 2005). This not only gets all of the team members involved at the very beginning, but also provides focus and identifies potential problem areas.

It is also important for the teams to understand the difference between cooperation and collaboration. Cooperation is where the multiple tasks of a project are divided among the team members, but each person works independently. Collaboration is the process where the finished product is produced via interactions among all of the members of the group working together (Paulus, 2005). True training in teamwork will come from collaboration, not cooperation. Collaboration has also been found to produce the advances in cognitive learning desired by project-based learning (Paulus, 2005).

Once the teams are created and properly prepared, the instructor still has work to do. It is the instructor's responsibility to ensure that the teams are functioning effectively. Part of that is looking for any missing characteristics that define an effective team.

What are those characteristics? While all papers had some slight differences, most of them agreed on the following:

1. Common goal (Tips for Effective Teamwork, 2015) : all team members agree on the final product and the process to create it

2. Organization: the team assigns roles and responsibilities to have everyone participating. For long-term projects, those roles can be switched among the team members (Teamwork and Working in Teams, 2002)

3. Group consciousness: each team member has the awareness that they are part of a team, and what they do can effect others. This characteristic includes respect for the other team members (Teamwork and Working in Teams, 2002) and trust in the other team members (Tips for Effective Teamwork, 2015)

4. Effective communication and interactions: the team members have a smooth means of sharing ideas and producing results

5. Cohesion (Tips for Effective Teamwork, 2015): The team members develop a smooth and effective process that allows them to function with little or no intervention; self-motivation and mutual support are a part of this characteristic

These characteristics address the main reasons group project teams fail, according to surveys conducted by students (Tips for Effective Teamwork, 2015). The primary reasons are disorganization, unclear objectives, separated or fragmented group members, lack of motivation, and conflicts among group members. Properly prepared and structured teams deal with all of those items except motivation and conflict resolution, both of which will be discussed later in this section. 
Just designing and supporting the team to have the right characteristics is not enough. There are key behavioral factors that must be operating to support team cohesion and effectiveness (Teamwork and Working in Teams, 2002). These keys are:

1. Cooperation: Positive interdependence is achieved when members of the team rely on each other to complete the project. They understand that their individual success is inherently linked with that of their other team members and with the success of the team as a whole.

2. Accountability: Individual accountability means that each team member is held responsible for his or her contribution to the completion of the project.

3. Encouragement: Promotive interaction implies that group members recognize the contribution of others in the team and give positive feedback for their accomplishments. They encourage each other towards the successful completion of their tasks.

4. Communication: Appropriate use of social skills is necessary because interpersonal and small group skills are critical to team success.

5. Analysis: Through group processing techniques, team members reflect on how well their team is functioning.

Most authors in the literature encourage the use of functionary roles to have each member of the group contributing to the cohesion. While specific roles differ, the most common ones are a Team Leader, a Scribe, a Facilitator, and a Liaison (Teamwork and Working in Teams, 2002). The Team Leader's role is rather obvious. This is the person who keeps everyone on track and on schedule. The Scribe is the note taker for meeting, and also the "consolidator", or the person to produce the final end result, if the group is producing a written end result and have difficulty (or can't use) a shared document that allows the ability to "collapse" or integrate separate updates.

The Facilitator is used in brainstorming and problem solving sessions. This person moderates the conversation and ensures everyone participates. The Facilitator is often the person who initially attempts to resolve conflicts among group members, especially if the Team Leader is one of the people engaged in the conflict.

The Liaison is an interesting role. It is not always used, but is finding more prominence among project-based learning, especially ones designed to get assistance from remote sources. The Liaison is the person who maintains contact with external resources, like professional advisors or colleagues at other locations. Instead of being swarmed by every member of the group, this one person gathers the information or questions desired by everyone and brings those items to the external contact.

It's easy to say that we want to have effectively-running project teams, but what does it mean to be effective? The literature addresses that, too. While there is no universal measures, there are four items that most of the experts feel are crucial success measures: effectiveness, efficiency, satisfaction, and achievement (Hoegl \& Gemuenden, 2001). Effectiveness simply measures whether the team fulfilled on their goals. Efficiency measures how quickly they could resolve issues and research key information. Satisfaction measures how pleased the group members are with their process, and achievement measures what the students learned during the project.

To fulfill on these measures, and be an effective team, there are several common problems that the instructor should be attentive to, and support the teams in resolving them. Those problems are (Roberts \& McInnerney, 2007):

1. Student apathy

2. Lack of group or social skills

3. Free riders, those group members who don't want to do the work but get the same grade as everyone else

4. Imbalance or inequality of ability; some group members seem naturally more capable than others

5. Poor distribution of roles and responsibilities

6. Ignoring some group members, or some just stop participating

7. Conflict among team members 
So what can be done to alleviate these problems? As suggested by Roberts and McInnerney, student apathy can be resolved with any combination of the following: developing rapport with games or exercises, providing personal motivation like extra credit or other bonuses, and promoting the value of the assignment. The lack of group or social skills can be handled by additional training (either in class or outside) or small assignments that build a social presence (like discussion board posts or weekly journals). Free riders have to be identified and encouraged to participate. If they don't, they are appropriately punished with a lower grade or extra work. A reward system also works well for a skill imbalance, only this time reward team members for applying extra effort. Then those who work hard to improve themselves will gain the reward.

The next two problems can only be effectively handled by monitoring the groups' progress (Roberts \& McInnerney, 2007). The instructor must maintain contact with the team, ideally through more than one person (like the Team Leader AND the Liaison), to ensure that everyone is participating and that roles and responsibilities are appropriately and equally apportioned.

Conflict Resolution is widely regarded in the literature as an important skill in effective group projects. While all instructors hope that their student groups will smoothly operate with no personal conflicts, they realize that is an unrealistic hope. It is best to prepare your groups for resolve conflicts by conducting a workshop, even a roleplaying exercise, before beginning the project (Teamwork and Working in Teams, 2002). The general advice provided in such exercises seems fairly universal (Teamwork and Working in Teams, 2002):

1. Keep the conversation focused on the common goals and group interests. Prevent personal opinions.

2. Maintain a sense of calm. Once people get angry and raise their voice, rationality disappears and emotions run high.

3. Use personal statements ("I feel like...") instead of accusatory statements ("You tried to hurt me.")

4. Listen to both sides of the disagreement before rushing to judgement.

5. Look for a compromise that satisfies everyone. Don't play favorites or "whose turn is it to win?"

The Conflict Resolution Consortium at the University of Colorado-Boulder provides some more detailed advice (Burgess, n.d.). According to them, the first priority is to restore group cooperation and cohesion. Try to see the other person's point of view. You don't have to agree with him or her, but don't simply say, "You're wrong" or "Get over yourself." Listen to the person's fear, and then attempt to diffuse them. Often their fears are what are controlling the situation, and calming them will soothe them and allow for a smoother conversation. A similar process can be done for any intense emotions that erupt. You can acknowledge that someone has gotten excited ("I can see that this is very intense for you.") and then encourage them to discuss the source of those feelings. This helps diffuse it by dealing with the CAUSE of the emotions instead of the emotions themselves.

The University of Melbourne Law School has some additional points: (Tips for Effective Teamwork, 2015)

1. Identify the cause of the conflict

2. Distinguish how the conflict affects the team and the task

3. Brainstorm a solution that does not hurt anyone, benefits as many group members as possible, and furthers the group's common goals

4. Agree on the steps to take to resolve the conflict and implement the solution

5. Document the process and the proposed solution. This prevents anyone from later saying that the conflict wasn't really resolved

\section{Tips for Effective Teamwork}

As a participant, and later a coach, for the Team Management and Leadership Program (TMLP), I have seen what promotes a group of diverse personalities and experiences merge into a highly effective team. Many of the successful aspects of the TMLP apply to project-based learning, as reflected in the literature.

The first, and most crucial, step is called "Background of Relatedness." It is nearly impossible to get a group of strangers to smoothly work together. It is important for group members to bond over familiar and shared 
experiences or interests (How to Survive Virtual Group Work, n.d.). This can be handled by having them share personal stories on Facebook or a private Discussion Board. Allow them to create threads based on personal interests, so that they can see how many other students share their interests.

Once they know each other, the next step is easier. They should create a clear and measureable result. All members of the group should agree on the final result, and it should have specific parts and aspects that can be visibly seen. This allows the group members to determine when they are done, because it contains everything they intended (Oakley, Felder, Brent, \& Elhajj, 2004).

Once a clear intended result is visible, the group members can determine the process to fulfill on that intention. They should get specific, and prioritize items in chronological order (Oakley, Felder, Brent, \& Elhajj, 2004). These items should be specific, detailed, and small. It doesn't matter if you have many of them. Keeping it simple allows each individual task to be easily understood and achieved (How to Survive Virtual Group Work, n.d.).

The group members should report the completion of tasks to the Group Leader, who maintains a checklist, calendar, or other means of tracking the project (How to Survive Virtual Group Work, n.d.). It is important for the Group Leader to have a clear picture of what has been accomplished, what remains to be accomplished, and what items might be falling behind. The Group Leader should communicate the progress to the rest of the team frequently (in class environments, that means at least twice a week) and the group members should communicate their progress just as frequently.

As tasks are completed, the Team Leader should acknowledge the group members for their efforts, and even periodically reward them for their efforts. This maintains the students' motivation and creates a sense of accomplishment that is crucial to their self-esteem.

\section{Tips for Collaboration}

The intent of many of these group projects, especially in higher education, is to promote collaboration (Lou \& MacGregor, 2004). For collaboration to be effective, there are key skills necessary: interpersonal and social skills, group management skills, and inquiry skills. Inquiry skills include the ability the clarify information, infer missing information from existing data, and judge what information is most crucial or most appropriate (Lou \& MacGregor, 2004). To build social skills, many experts suggest having the students share accomplishments or success stories each week as the project progresses (Sull, 2015).

Building these skills require examples, class exercises, and "best practices" pointers (Sull, 2015). These exercises should allow the students practice both levels of collaborative interaction. Low-level interaction involves activities like clarifying facts using defining questions, identifying the limits or boundaries of information, accepting and integrating information, declaring facts., and evaluating information (Lou \& MacGregor, 2004). High-level interactions involve presenting and examining alternatives, questioning ideas, cognitive elaboration and explanation, and organizing information.

\section{Online Collaboration}

With today's technology, it is thought that collaborative group projects can now be done easily, as information and technical experts are only a mouse click away. However, the use of online collaboration carries its own challenges, and it is important that instructors are aware of those when planning online collaboration projects (Whatley, Beer, \& Staniford, 2001). These challenges are:

1. Different schedules, work pace, and time zones

2. Impossible face-to-face opportunities

3. Secure file sharing

4. Different computer platforms or applications

5. Different file formats 
The greatest challenges involved in the use of online tools for collaboration are the diversity of technology and distance of the group members. Some may be part-time students who work full-time. Some may be in time zones as much as five or six hours apart. Arranging a mutually-available time for the group members to speak in person can be difficult.

The most common communication tools are email, discussion forums, text messages or instant messaging, online conference tools like GoToMeeting, blogs, and wikis. These are good for sharing ideas, but cannot be used to produce the end result. This limitation often causes them to use online tools for building the end result.

If the online tool has its own design and packaging, the use of an online tool to share ideas and build the product can move smoothly. However, most students simply use a file sharing program like Google Docs or Dropbox. This can cause serious problems.

Many online file sharing tools are only repositories. They can hold files of any type. There is typically one version of the file (unless the users themselves maintain historical copies). The file is downloaded, edited, and then uploaded again. There is no control to prevent two people from downloading the same file and uploading two different versions, thus losing the information added by the previous updater. File updates must then be carefully monitored and handled by one team member exclusively.

To bypass this, some teams might use an application like MS Word that can track changes. Thus, each member of the group can approve any changes before they are integrated into the document. This can have problems, too. The different group members might have different versions of the Microsoft Word application, which would use the Track Changes differently. Worse, if any team member has a Mac or Unix system instead of a Windows system, the application used to read MS Word documents (like Open Office) might not track changes at all, or mark them differently.

To alleviate this, the instructor should investigate appropriate online tools. The instructor would look for ones that manage documents or files itself, or ones that are operating system independent. After testing these tools, the instructor would then suggest that the students use them. In this fashion, the instructor can ensure that everyone is using the same tools, and prevent the problems that can occur from inconsistent or incompatible applications.

\section{CONCLUSION}

Project-based learning and group work are valuable tools for education. They teach teamwork and group dynamics, encourage a deeper and broader understanding of the course material, and foster higher-level cognitive abilities. However, these results can be hindered if the project and the student teams are not properly prepared and supported. The students must be prepared for how to effectively work in teams, and provided with the same online tools that facilitate sharing their ideas and formulating their end product.

Once student teams are created, they should be monitored and observed to ensure that the characteristics and keys of effective leadership and collaboration are present and working. Any disputes or conflicts should be resolved quickly, before it shatters the cohesiveness of the work group.

\section{AUTHOR BIOGRAPHY}

Robert Ekblaw is currently an Associate Professor in the School of Business and Computer Technology at Hudson Valley Community College and an Adjunct Lecturer at Siena College. From 1991 to 2006 he was a business consultant for Breakthrough Consulting Services, providing both customized software solutions and also providing business leadership training in such aspects as Team Building, Large Project Scheduling, and Time Management.

A 1986 graduate of the University of Illinois and a 1991 Masters graduate of Rensselaer Polytechnic Institute, Prof Ekblaw has been involved with the Team, Management and Leadership Program (TMLP) since 1995. The Team, Management and Leadership Program is a highly-regarded international leadership and team building training program, and is an advanced training program among the courses provided by Landmark Worldwide. He has 
implemented many of the concepts of the TMLP into his courses since 2007, with highly effective results. Email: profekblaw@gmail.com

\section{REFERENCES}

Burgess, H. (n.d.). Group Projects. Retrieved May 8, 2015, from Beyond Intractability: http://www.beyondintractability.org/educationtraining/group-projects

Collaborative Learning: Group Work. (2014, July 6). Retrieved May 2, 2015, from Cornell University Center for Teaching Excellence: http://www.cte.cornell.edu/teaching-ideas/engaging-students/collaborative-learning.html

Hoegl, M., \& Gemuenden, H. G. (2001, Jul-Aug). Teamwork Quality and the Success of Innovative Projects: A Theoretical Concept and Empirical Evidence. Organization Science, 12(4), 435-449.

How to Survive Virtual Group Work. (n.d.). Retrieved April 30, 2015, from eLearners.com: http://www.elearners.com/onlineeducation-resources/online-learning/how-to-survive-virtual-group-work/

Lou, Y., \& MacGregor, K. (2004). Enhancing Project-Based Learning Through Online Between-Group Collaboration. Educational Research and Evaluation, 10, 419-440.

Oakley, B., Felder, R., Brent, R., \& Elhajj, I. (2004). Turning Student Groups into Effective Teams. Journal of Student Centered Learning, 2(1), 9-34.

Paulus, T. M. (2005). Collaborative and Cooperative Approaches to Online Group Work: The impact of task type. Distance Education, 26(1), 111-125.

Roberts, T., \& McInnerney, J. (2007). Seven Problems of Online Group Learning (and Their Solutions). Educational Technology and Society, 10(4), 257-268.

Sull, E. C. (2015). Keeping Teamwork Alive, Motivated, and Enthused! (R. Kelly, Ed.) Student Collaboration in the Classroom, 8.

Tarricone, P., \& Luca, J. (2002). Successful teamwork: A case study. HERDSA Proceedings (pp. 640-646). Perth, Australia: Higher Education Research and Development Society of Australia.

Teamwork and Working in Teams. (2002). In J. Abarca, Introductory Engineering Design: A Projects Based Approach (pp. 3954). Boston: IEEE.

Tips for Effective Teamwork. (2015, April 24). Retrieved May 12, 2015, from University of Melbourne Law School: http://www.law.unimelb.edu.au/lasc/professional-skills/tips-for-effective-teamwork

Whatley, J., Beer, M., \& Staniford, G. (2001). Facilitation of Online Student Group Projects with a Support Agent. Proceedings of the Autonomous Agents'01 Workshop on Agents Supported Cooperative Work. Montreal, Canada: IBM TJ Watson Research Center. 


\section{NOTES}

